\title{
Irony Explanation Mechanism under Cognitive Perspective
}

\author{
Meixian Bai
}

School of foreign languages, Neijiang Normal University, Neijiang, 641100, China

\author{
Key words: Irony, Conceptual integration theory, Cognitive mechanism, Space conflict
}

\begin{abstract}
This paper tries to apply conceptual integration theory to study and explore irony on the basis of psychological space. It is found in example analysis that, "four-space" model fails to fully reasonably explain cognitive process of irony meaning, because irony effect is not based on similarity of relevant space to a large extent, but space conflict of each other serves as the trigger mechanism. Thus, this paper introduces space conflict, space docking and space transition to explain cognitive thinking process of irony.
\end{abstract}

\section{Introduction}

Irony is a common linguistic phenomenon and has been focused on by domestic and overseas theory scholars. In traditional language theory, irony is studied as a rhetorical phenomenon. As pragmatics, psychological linguistics and cognitive linguistics rise, different theories and research approaches enrich irony research results and specify cognition of irony. Linguistics mainly studies the relationship between surface meaning of irony and the meaning to be expressed. For example, the view of pragmatics expert Grice ${ }^{[1]}$ is that, irony is a special language use form, and implied meaning replaces explicit meaning. He explains irony as violation of cooperative principle and especially violation of quality principle. However, he does not explain why the speaker will express the intent from a reverse side. Thus, Leech's politeness principle and face theory of Brown \& Levinson explain irony as an indirect compensation strategy taken to keep harmonious interpersonal relationship from the perspective of sociology. Disguise principle of Clark \& Gerrig studies features of irony from the perspective of mental motivation. Sperber \& Wilson put forward Mention Theory from the perspective of perception and restoration. They regard language as echo and believe the listener adds ironic attitude to his speech in combination of language environment through the echo and reflects the speaker's attitude. Mention Theory solves mental motivation problem of irony generation, but the response is often excessively generalized. Some ironies are not ironies actually, and the echo cannot restore all attitudes of the original speaker. Giora's indirect negation theory analyzes the essence of irony from semantic features. Utsumi's implicit exhibition theory absorbs core contents of classical theory, Mention Theory and disguise theory, proposes necessary conditions and sufficient conditions to form irony and explains the essence and differentiation mechanism of irony. However, he fails to discuss irony generation and understanding in detail ${ }^{[9]}$. This paper discusses explanatory power of irony based on conceptual integration theory in cognitive linguistics and tries to introduce other cognitive mechanisms to construct cognitive framework understanding diagrams.

\section{Explanation of irony by conceptual integration theory}

\section{Brief introduction to conceptual integration theory}

Conceptual integration theory originates from psychological space theory and combines research results of neurosciences, cognitive science, psychology and linguistics. Cognitive linguistic theory is officially proposed by Fauconnier. Conceptual integration in this theory refers to integration of psychological space. Psychological space is of local structure and expands with our thinking and communication so that sub-division of our utterance and knowledge structure becomes possible. Conceptual integration theory systematically explains each psychological space maps mutually and generates interactive functions in verbal communication process. It aims to try to disclose cognitive thinking mode behind online construction of verbal meaning. Its core theory is "four-space" model theory which consists of four spaces: two input spaces (Input 1 \& 2), Generic space formed through 
two input spaces mapping correspondingly. Generic space reflects shared and more abstract structure and organization of input space and stipulates core cross-space mapping. Two input spaces partly project to the fourth blending space. Then, emergent structure is generated through interactions of three mutually related psychological cognition processes: combination (conceptual integration combines ingredients in input space; nonexistent relationship in the input space is shown), perfection (conceptual integration combines the structure, background knowledge in subconscious and structure to gain the maximum perfect mode) and expansion (conceptual integration will conduct psychological simulation as per the principle and logic in blending space to further perfect the blending space). Simply speaking, conceptual integration is basic cognitive operation of psychological space and applies online and dynamic cognitive mode construction significance. It is a new research perspective of cognitive linguistics after conceptual metaphor theory. Scholars try to linguistic theory and practice to prove explanatory power of conceptual integration theory. Some compare conceptual metaphor theory and conceptual integration theory; some apply this theory in translation theory and practice; some apply it to discuss the image of poems; some apply this theory to explore some linguistic phenomena, such as humor, interlanguage, Zeugma and two-part allegorical saying. Whether will this theory provides a rational explanation of irony cognition and understanding?

\section{Analysis and discussion of irony example}

Irony means to use opposite sentences to express the real intention ${ }^{[2]}$. Opposite semantic words are often used to express the positive meaning or use the positive wordings to express the opposite meaning. The definition and classification of irony are different in Chinese and English cultures, but the essence is same. In English irony, irony is generally classified into verbal irony and situational irony. The classification basis is whether the hidden meaning of irony is reflected through a word or depends on language environment.

Verbal irony is taken as the analysis object as follows:

Example 1:

Mother: How about Jim's study?

Teacher: Well, he is diligent and seldom reads more than two hours per week.

Translation:

妈妈: 吉姆学习怎么样?

老师：不错，他是个勤奋的学生，每周读书时间很少超过两小时。

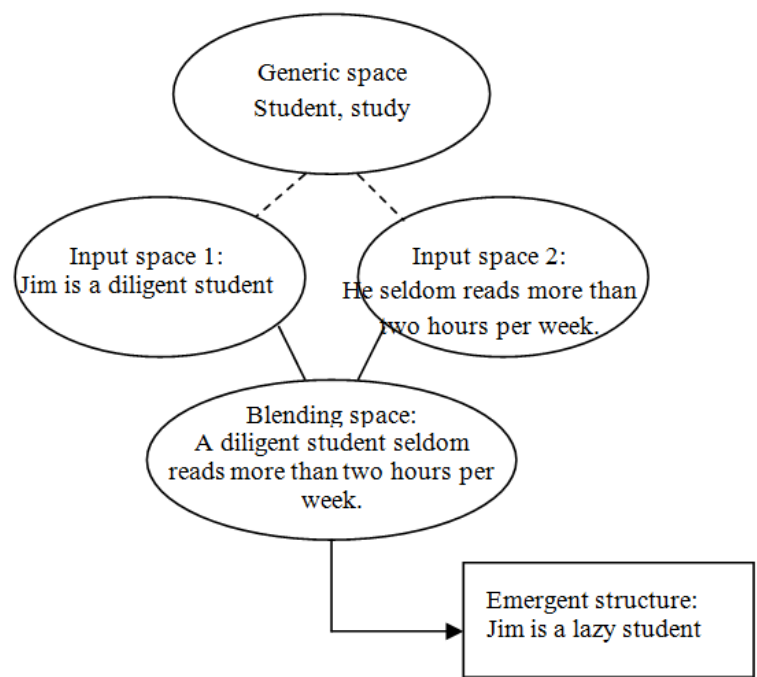

Fig.1. Example analysis of "four-space" model

It can be seen from the theoretical analysis diagram that, input space 1 is "diligent"; input space 2 is "seldom reads more than two hours per week"; generic space is "student, study"; two input spaces project to form blending space: A diligent student seldom reads more than two hours per week. 
Emergent structure is: Jim is a lazy student. Conceptual integration theory tells us that emergent structure is generated in blending space. But, how is emergent structure generated in detail? How is irony achieved? These cognitive processes are vague according to four-space model analysis of conceptual integration theory. So, it is necessary to further discuss cognition and understanding of irony.

\section{Understanding of irony with new cognitive mechanism}

\section{Introduction to new cognitive mechanism diagram}

In irony environment, surface meaning deviates from and conflicts with the real intention. The purpose of irony is to reach striking contrast and strong contrast through using implicit expression modes, complimentary and derogatory sense of words and language environment so as to reach special expression effect. If only four-space model of conceptual integration theory is applied to cognize and understand the irony, this lacks discussion on the essence of analysis objects and thus will influence cognition and understanding of irony meaning. The largest difference between metaphor and irony is that irony effect is reflected the conflict between surface meaning and real intention. During analysis of the cognitive psychological space, space conflict needs to be stressed. Therefore, this paper holds that based on four-space model, cognition and understanding of irony meaning are also related to three types of cognitive mechanisms of psychological space: space docking, space conflict and space transition. Before analysis of irony understanding process, it is planned to roughly define these cognitive mechanisms and give frame diagram.

Space docking means to try to connect conceptual coherent default expected values of a space input and the other space input to gain the correlation between the two spaces. Space conflict means when spaces cannot be connected, people will realize space input contradictions and thus trigger new understanding of space relation. Space transition refers to a process where a space is inputted to another new psychological space in order to eliminate space conflict after space input docking fails and space conflict is generated ${ }^{[3]}$. A fundamental factor triggering space transition mechanism is to discover space conflict in irony, i.e. find out inconsistent concept or deviation of each space input. Irony apperception often starts here. Space blending means to selectively extract space structures from space input and integrate them into a new psychological space. Reasoning is a basic thinking mode to judge correlation of objective things. It plays a decisive role in irony understanding process. In addition, psychological basis of space docking is correlation of each space input, though it seems that the speech of the speaker is not correlated, because he may convey an intention. It can be said that correlation itself is a kind of reasoning. Any reasoning will be based on language environment. Language environment is dynamic, including social context, cultural custom context, linguistic context and situational context etc. Once verbal communication happens, language environment will play a role. In view of this, during analyzing psychological cognitive mechanisms, language environment should be fully valued and stressed. Based on the above definition of cognitive mechanisms, frame diagram of irony cognition and understanding is shown in Fig.2: 


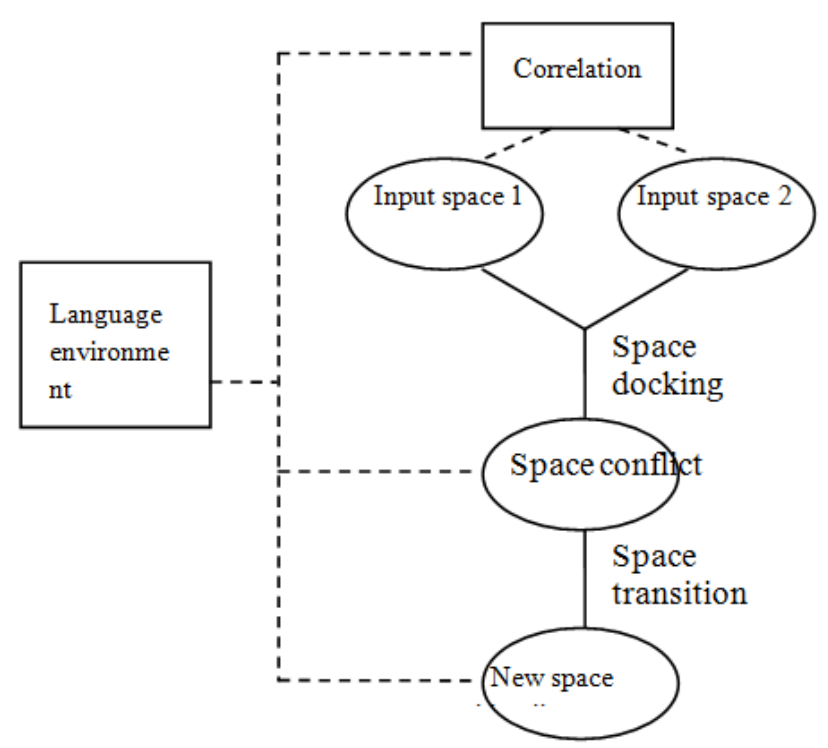

Fig. 2. Frame diagram of irony cognition and understanding

\section{Example verification}

Take Example 1 for example: input space 1 is “diligent”; input space 2 is "seldom reads more than two hours per week". Conceptual coherent default expected values of two spaces are inconsistent, and the two spaces are opposite semantically. So, it is hard for the two spaces to dock. Thus, space conflict is caused. Space 1 and Space 2 are correlated. In Example 1, the teacher impossibly answers a question with two unrelated sentences. The audience has to combine the language environment with the help of space transition, i.e. a mother inquires his child's learning situation. The teacher first uses the word "diligent" to evaluate the student, and then applies actual learning condition to verify the evaluation, i.e. "He seldom reads more than two hours per week." The learning situation described by the teacher is true, so the audience may easily transfer the words in input space 1 to another new psychological space (i.e. query about “diligent” evaluation). Meanwhile, the words in input space 2 are blended with this new space to gain new understanding: Jim is lazy in study.

Understanding diagram of Example 1 is as follows (Fig.3):

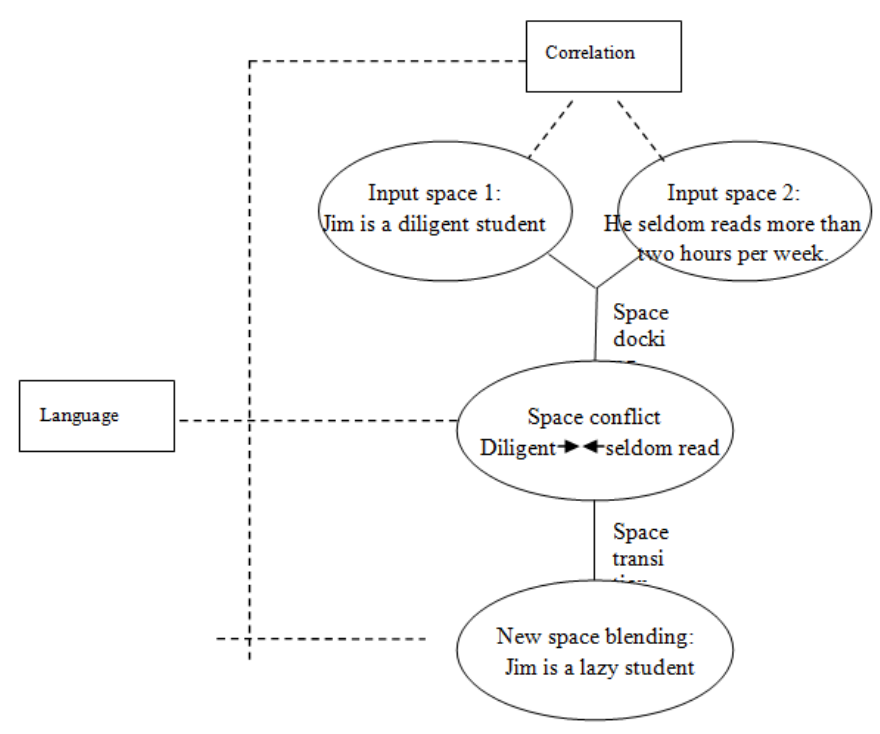

Fig. 3. Example analysis under frame diagram of irony cognition and understanding

As mentioned above, Except verbal irony, there is also situational irony. Whether is this understanding frame applicable to situational irony? The analysis of Example 2 is as follows: 
Example 2: Most of the abolitionists belong to nations that spend half their annual income on weapons of war and that honor research to perfect means of killing.

Input space 1 is "most of the abolitionists"; input space 2 is "spend half their annual income on weapons of war and that honor research to perfect means of killing". Semantic content of the two are inconsistent and they cannot achieve space docking. Input space 1 expresses the abolitionists are benevolent and tolerant people, while input space 2 expresses such ruthless and bloody people who spend half their annual income on weapons of war and that honor research to perfect means of killing. Input space 1 and input space 2 describe the same kind of people, but the concepts are opposite. So, space conflict is caused. The audience easily transferred to another new psychological space: are the abolitionists tolerant? According to language environment and the fact described in input space 2, the space may be blended easily: the abolitionists and their capacity are inconsistent, and they are falsely benevolent.

This is a typical situational irony: on the one hand, they call on to abolish the death penalty; on the other hand, they manufacture war machines in quantity, so their crocodile tears are disclosed. In the sentence, no single word shows semantic disconnection, but irony meaning is revealed through understanding an analysis with cognitive mechanisms, so the irony effect is realized.

\section{Conclusion}

Cognitive linguistics regards language as a cognitive activity, starts from cognition to study linguistic form, meaning and rules and actively explores how meaning is constructed in the brain. Conceptual integration theory is a cognitive process when people carry out creative thinking and also an important constituent part of cognitive linguistics. Four-space model of this theory is based on psychological space and similarity to show the generation process of emergent structure in blending space. Thus, it has strong explanatory power for many linguistic phenomena. However, in the irony, example verification finds the realization of irony effect is not based on similarity, but space conflict serves as the trigger mechanism to trigger formation of new psychological space. Hence, based on four-space model theory, we properly make cognitive frame diagram clear and concrete according to language cognition objects. In irony frame diagram, space docking, space conflict and space transition are introduced to more clearly know cognitive thinking of irony. The above analysis shows that irony comprehension process is not merely a part of cognitive mechanism used to explain non-direct meaning sentences, but also contributes to studying understanding mechanism of metaphor language. Therefore, it is of great significance to cognize and understand it.

\section{References}

[1] Leech, G. Principles of pragmatics. London and New York: Longman Group Limited, 1983.

[2] Brown, P. \& S. C. Levinson. Politeness: Some Universals in Language Usage. Cambridge: CUP, 1987.

[3] Clark, H.H. \& R.T. Gerrig. On the pretence theory of irony. Journal of Experimental Psychology General, 1984. 